www.jmscr.igmpublication.org

Impact Factor (SJIF): 6.379

Index Copernicus Value: 79.54

ISSN (e)-2347-176x ISSN (p) 2455-0450

crossrefDOI: https://dx.doi.org/10.18535/jmscr/v6i8.54

\title{
Measuring the Effect of the Follow-up Evaluation of the Training Exercises for the Tension of Supraspinatus Muscle Animation Injury and Some Physical and Functional Variables
}

\author{
Authors \\ Ahmed Atshanabd Al-Rida ${ }^{1}$, Imad Kadhim Yassir ${ }^{2}$, Ali Jasim Swadi ${ }^{3}$ \\ University of Thiqar, Iraq \\ Email's: ${ }^{1}$ Medo1978alrekabi@gmail.com, ${ }^{2}$ imadkadhim@pe.utq.iq, ${ }^{3}$ jasim.ali56@yahoo.com
}

\begin{abstract}
The research included one of the injuries that most athletes fusser from while practicing various games which is the injury of Supraspinatus muscle animation of the shoulder joint. The study aimed to prepare training exercises for this type of injury according to the functional and physical aspects of the injured athletes, as well as evaluating these exercises according to different stages of applying. The researchers used the experimental approach and design an experimental group of different stages that is suitable for the problem. The population of the study included the players of shoulder joint injury coursed by musculoskeletal inflammation, premier league participant and participants of the qualifying for the premier league of 2017-2018, in Thi-Qar city. The total of the research community is 12 players. However, the researchers concluded that the praxis of various exercises has a positive effect on the inflammation of supraspinatus muscle animation. Thus, the evaluation of training exercises during different stages showed the amount of improvement through the successful application of these exercises, which reflected on the work of the muscle physically and functionally.
\end{abstract}

\subsection{Introduction and importance of the study}

Most countries in all over the world start practicing the sport exercises for medical purposes as it is an irreplaceable necessity. It is a must for the specialists of physical injuries and sport rehabilitation to use various techniques and scientific methods. In recent years, there has been a great and varied development in the methods and techniques used in physiotherapy; this shows the positive role of rehabilitation exercises which are considered as one of the most important means at this stage because of their positive impact. The researchers has realized that the sinew of supraspinatus muscle animation in the shoulder joint and Common in the rounding and refraction of the arm movements is one of the most muscular tendons because of its direct relation with muscles To perform joint movements of the muscles of the round cuff and this makes him vulnerable to injury; This is on one hand and lack of interest in strengthening it, whether through good warm-up and associated with the complete lengthening of muscles or through the use of weights in an inappropriate manner during training on the other. However, the importance of the research in an attempt to prepare training exercises in the injury 
of the sinew of supraspinatus muscle animation and the development of muscle work physically and functionally, also develop the work of the joint as a whole of injured athletes.

\subsection{Statement of the problem}

Many individuals are exposed to muscle tendon injury due to various and different causes. The method of diagnosis and treatment varies according to the type of injury. The sinew of supraspinatus muscle animation injury will inevitably lead to the occurrence of dysfunction, physical and biochemical in the muscles working on the shoulder joint. Pain also realized even if the joint is good so that a movement problem and weakness in performance. However, though the experience of the researchers it is shown that the inflammation of sinew occurred because of overvoltage in early time. It is also one of the common injuries for players of various sports that the arm is used to throwing and tossing; It is also of the injuries that the players suddenly affected and can increased to a serious injury. Thus, through going on the previous studies, the researchers found that there are no studies that talk about the inhabitation of supraspinatus muscle animation from one hand and the previous level of inhabitation is not approver on the other hand; so, all that leads the researchers to do this study for finding suitable solutions.

\subsection{Objectives of the study}

1. Preparation of training exercises for the injury of supraspinatus muscle animation according to physical and functional principles of injured athletes.

2. To identify the size of assessment of rehabilitation exercises at various stages of the research sample.

3. To identify the impact of rehabilitation exercises of injuring the sinew of supraspinatus muscle animation and some functional and physical principles of the research sample.

\subsection{Hypothesis of the study}

1. There exists an effect of rehabilitation exercises on the injury of supraspinatus muscle animation and some physical and functional principles for injured athletes.

2. Differentiation of the evaluation level in the stages of the training exercises application in improving the muscles of shoulder joint of the injured athletes.

\subsection{Research Areas}

\subsubsection{Human domain}

Athletes injured by some individual and differential games that arms are used frequently such as volleyball, handball and shooting games in Dhiqar city.

\subsubsection{Time domain}

01/09/2017 to $31 / 01 / 2018$

\subsubsection{Place domain}

Laboratory of Physis, Faculty of Physical Education, Dhiqar University and Sports Club of Dhiqar City.

\section{Theoretical Studies}

\subsection{Rehabilitation}

It is a group of sciences specialized in the anatomy of the functional, anatomical and mechanical aspects of the body's work during motor activity. Moreover, the ways of exercise, prevention, treatment, nutrition and all standards happened in the body during the physical exercises $^{(1)}$.

\subsubsection{Supraspinatus Muscle Animation Sinew}

The rotator cuff tendinitis is the most vulnerable to injuries of the four muscles. The Supraspinatus Muscle Animation Sinew is also vulnerable to injuries and inflammation especially while passing under the acromion. The patient may feel shoulder joint ache even the shoulder itself is hale ${ }^{(2)}$.

\section{Research methodology}

The researchers use the experimental method to the only experimental group design of various stages of evaluation.

\subsection{Research community and Sample}

The researchers identified the research community in a deliberate way. The community included those athletes who are affected by inflammation of Supraspinatus Muscle Animation Sinew in Dhiqar 
sports clubs for individual sports such as shooting games, handball and volleyball. 12 players were selected, two of them have been excepted as the doctor advised so 10 players are the sample of the study in $83.3 \%$. To make sure of the injury place, a magnetic resonance test has been done in Al-
Husain Educational Hospital. However, through the report of the magnetic resonance test and specialized doctor, the place, percentage and intensity of injury has been identified. The following table shows the harmonization of variables:

\begin{tabular}{|c|c|c|c|c|}
\hline Variables & Measuring unit & Arithmetic mean & Standard deviation & Torsion coeffient \\
\hline Length & $\mathbf{C m}$ & $\mathbf{1 7 . 6}$ & 3.501 & 0.583 \\
\hline Age & One year & 23.0 & 2.32 & 0.639- \\
\hline Weigh & Kg & 72.0 & 4.47 & 0.723 \\
\hline Degree of pain & One Degree & 74.3 & 0.63 & 0.720- \\
\hline Bend forward & One Degree & 112.4 & 8.55 & 0.912- \\
\hline The back tide & One Degree & 21.60 & 5.35 & 0.897 \\
\hline Dimension & One Degree & 111.8 & 9.56 & 1.004- \\
\hline Rounding & One Degree & 17.60 & 5.61 & 0.330 \\
\hline Maximum power & Kg & 6.130 & 0.53 & 0.462- \\
\hline Carry power & Repetitive & 4.000 & 1.33 & 0.030- \\
\hline
\end{tabular}

\section{3 means and tools used in the research}

Personal interview, tests, measurements and notes.

\subsection{Tools and devices of collecting data}

1. Calculator (1)

2. Laptop (1)

3. A video Camera (1) Sony

4. Medical properties such as Ditol, cotton, gauze, adhesives tapes to put the clamp on the body and razor blades to remove the hair from the place of the clips.

5. Electronic designing device (EMG)

6. Dynamometer device for measuring the muscles power.

\subsection{The research practical procedures}

\subsubsection{Determine the research variables}

The physical and functional variables were determined due to its importance for ensuring that the muscles work normally. Moreover, through going on educational resources and specialists' opinions it is realized that they are very $\operatorname{important}^{(*)} 1$. However, the physical variables were determined and named as the muscles strength, bearing the muscles work, level of pain

*-Hassan, A, Ali, sport and health, Aleskandria, Dar Almarif publishing, 2011, p:15

Albasri Ebrahim, sport injuries, Baghdad, Dar Alhuria publishing, 1978, p:93 and top and area of electrical work during the work of the muscles strength and tolerance which are considered as very important functional and physical variables for the safety of muscular work.

\subsubsection{The Exploratory Experiments}

Many experiments related to the first exploratory experiment have been done on 25/10/2017. It took place at nine o'clock in the morning with a sample of three players in the laboratory of physis, faculty of physical education, Dhiqar University. Another exploratory experiment with same standards and conditions has been done after seven days to ensure the quality of tests, identify the validity of the used tools and devices, identify the staff and their number ${ }^{(*)}$, identify the needed time for making the test and finally identify the obstacles that face the experience.

\subsubsection{Measurements and Tests Used}

Many tests that must be subjected to many conditions in standard measurement have been used. The researches have done such tests with the help of medical and sport rehabilitation specialists. However, the tests included the identifying if pain level through a clinical examination by specialist $(* * 2)$ in the field of

(**) Alkhatib ,N. board joints and fractions, Alnaseria sport club 
joints and fractures, test the strength of the muscle and testing of electrical activity (EMG) and its as follow:

First: Identifying the measurement of pain degree through diagnosis during rest and movement at different angles as follow:

1. Pain during rest time (5 Degrees).

2. Pain when pressing the injury area (4 degrees).

3. Pain when moving the arm up aside at 45 angle (3 degrees).

4. Pain when moving the arm up aside at 60 angle (2degrees).

5. Pain when moving the arm up aside at 90 angle (1 degree).

Therefore, the maximum pain degree is (7) and the minimum is (Zero); this means that the higher the degree, the greater the pain and vice versa.

Second: The test name, (measuring the maximum power of the shoulder muscle) ${ }^{(3)}$

Aim of the Test:

The aim is to measure the maximum power of the injured arm and the maximum effort could be produced to perform one involuntary muscle contraction. It is shown in the form (4)

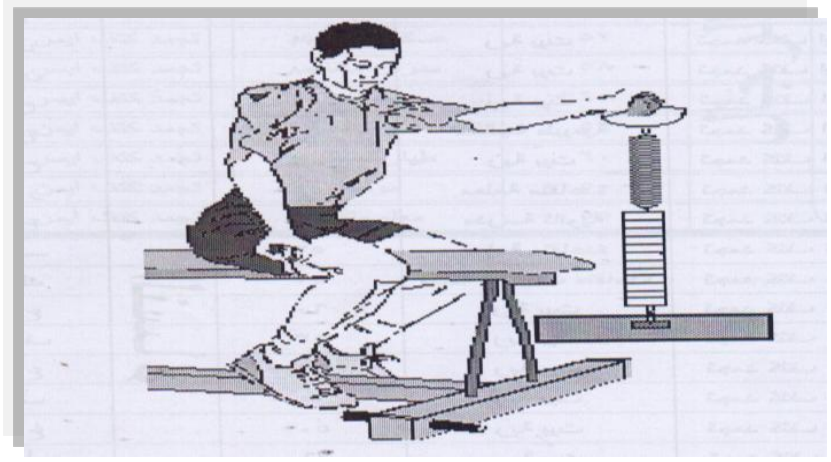

Form No. (1)

Tools used in the test:

The tools that were uses are Dynamometer along with a chair, Hollow tubular steel fist and lightweight metal chain.

\section{Performance Description}

Mjeed, board joints and fractions, Alshatra public hospital.
The examiner sits down on the dynamometer chair while his trunk is elongated, looking ahead, and his arms are lying down holding the chain that is connected to the device; then the examiner is required, with a particular sign, to move his injured arm aside with a maximum force.

\section{Method of accounting the result}

The maximum power is being accounted for the injured arm and the nearest kilogram the device calculates. The resistance is determined by pulling the arm to a specific weight and is extended to maximum capacity.

Third: identify the tolerance power of the injured $\operatorname{arm}(2)$

The test name is, examine the arm lift extended to the side (30 seconds).

Aim of the test: measuring the strength of the dorsal muscle.

Tools and devices used in the test are a $50 \mathrm{~cm}$ high terrace, Electronic stopwatch and $1.5 \mathrm{Kg}$ Dumbbells.

\section{The way of performance}

Sitting upright on a terrace while the injured arm is hanging down and fingers sign at the body handling the $1.5 \mathrm{Kg}$ dumbbells; when the humerus becomes horizontal in a 900c with the body at the articular joint and return the arm down fully stretched. The practice is repeated many times as possible as it can be.

\section{Accounting the results}

The correct number of times is calculated in 30 seconds.

\section{Accounting}

The number of correct attempts that has been done within 30 seconds is accounted as it is shown in form (2)

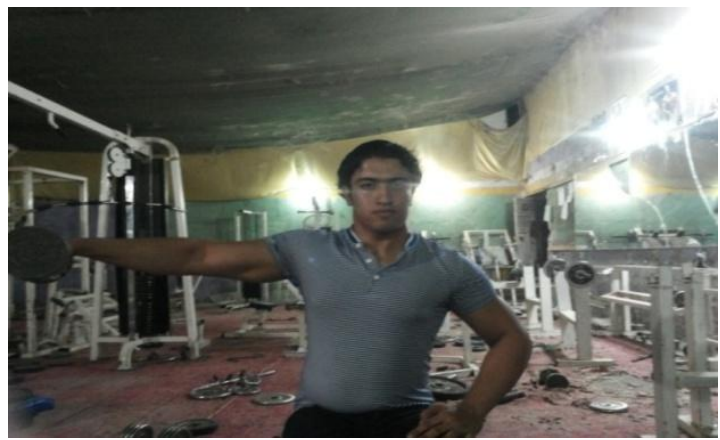

Form No. 2 
Fourth: measuring the electrical signal (summit \&space) for the Supraspinatus Muscle Animation

\section{How the device works}

The modern EMG device is a device does not weight more than 390 gram connected to the player's waist. The device sends Bluetooth signals of the muscles activity to another device connected to the laptop. The modern EMG device distinguishes in enabling the player to perform all types of activities such as bounce, rotation and running fast for $40 \mathrm{~m}$ of the receiver's place to record and save EMG signal; this signal determines the time of starting and the end the activity of the muscle and its power with the axes of the muscles working in motion.

\subsubsection{The pre-tests}

The pre-test is considered be the means that enable us to recognize the place, real level of the injury and the starting point of the researchers. Group of tests have been applied to be a signal point to set the principals for ensuring the accuracy of the results on one hand and the effectiveness of rehabilitation activities on the other. The applied test included the pain level, the maximum power and the force toleration. It took place on Sunday, 4/11/2017, at 9:30 am, at faculty of physical education, Dhiqar University at the same time of maximum test and force toleration. All participants attended the as well as the assistant staff.

\subsubsection{The rehabilitation program}

The rehabilitation activities have been prepared for the injured Supraspinatus Muscle Animation for eight weeks, three rehabilitation units weekly. The total number of rehabilitation units is 24 . It included various and suitable activities on the shoulder joint such as rounding, bending, stretching forward and backward, lifting and lowering the arm. The researchers took into consideration the repetition and differences in activities performance with varying performance in terms of increase and gradation in ranges and mobility. However, the purpose was that to develop the movement range of joint, rubber rotary palm muscles and increasing the muscle's power. The researchers also ensured the stretching exercises in order to stimulate the largest number of movement units to participate in the work and return the injured to the condition of the natural muscle before injury. The rehabilitation program was taken a care in the term of appropriate rest periods and the ability of the injured player to return back to the work.

\subsubsection{The main Experiment}

\section{* First section}

The first section of the main experiment includes four weeks with three rehabilitation units per a week. The first week consists of stable power with negative strength exercises as it shows in the program details. However, after completing the first time period of rehabilitation, environmental tests have been done according to the available details for ensuring the development and respond ability of the muscle.

\section{* Second Section}

The second section of the main experiment includes four weeks with three different rehabilitation units weekly, various exercises are applied with different power with using the moving power and strength power that aim at increase the muscle power; It also develops the returning shoulder muscle by neuromuscular adjustment that increase the muscular power due to regulating the work of fibers and regulate the flow of nerve cells.

\subsubsection{The post-Tests}

The post-tests have been done after finishing the application of rehabilitation exercises that the researchers prepared on the groups of 7/1/2018.

\subsection{Statistical Means}

The researchers use the statistical mean (SPSS), version (20) in analyzing the results; using arithmetic mean, standard deviation, torsion coefficient, Fred man percentage and impact size.(4) 
4. View, Analyze and Discuss the Results 4.1. View, Analyze and Discuss the Results of test of pain level, maximum power, sustain power and space of EMG in pre, during and post measurements
The following table shows the standards deviations, arithmetic means, minimum and maximum power, power toleration, space of EMG in pre, during and post measurements.

\begin{tabular}{|c|c|c|c|c|c|c|}
\hline Tests & Measurements & mean & S.D & Stages & $\begin{array}{c}\text { minimum } \\
\text { degree }\end{array}$ & $\begin{array}{c}\text { mximum } \\
\text { degree }\end{array}$ \\
\hline \multirow{3}{*}{ Pain level } & \multirow{3}{*}{ Degree } & 3.74 & 0.63 & Pre & 4.15 & 7.00 \\
\hline & & 2.37 & 1.02 & During & 7.00 & 12.0 \\
\hline & & 0.12 & 0.46 & Post & 11.5 & 19.0 \\
\hline \multirow{3}{*}{ Maximum power } & \multirow{3}{*}{$K g$} & 6.13 & 0.535 & Pre & 5.15 & 7.00 \\
\hline & & 9.40 & 0.966 & During & 8.00 & 11.0 \\
\hline & & 14.60 & 1.577 & Post & 12.5 & 18.0 \\
\hline \multirow{3}{*}{ power toleration } & \multirow{3}{*}{ How often } & 4.00 & 1.337 & Pre & 3.00 & 7.00 \\
\hline & & 8.00 & 1.059 & During & 8.00 & 11.0 \\
\hline & & 18.0 & 0.994 & Post & 20.0 & 20.0 \\
\hline \multirow{3}{*}{$\begin{array}{l}\text { Peak electrical activity } \\
\text { of maximum force } \\
\text { EMG }\end{array}$} & \multirow{3}{*}{ Microvolt } & 855.5 & 153.3 & Pre & 6.50 & 1200 \\
\hline & & 531.0 & 104.9 & During & 318 & 677 \\
\hline & & 281.8 & 40.87 & Post & 165 & 282 \\
\hline \multirow{3}{*}{$\begin{array}{l}\text { Space of electrical } \\
\text { activity of } \\
\text { force EMaximum }\end{array}$} & \multirow{3}{*}{$\begin{array}{c}\text { Microvolt/seco } \\
\text { nd }\end{array}$} & 82.82 & 17.51 & Pre & 62.0 & 128 \\
\hline & & 65.13 & 8.202 & During & 51.0 & 80.0 \\
\hline & & 42.53 & 8.161 & Post & 30.2 & 58.3 \\
\hline \multirow{3}{*}{$\begin{array}{l}\text { Peak electrical activity } \\
\text { of maximum force } \\
\text { EMG }\end{array}$} & \multirow{3}{*}{ Microvolt } & 941.6 & 131.8 & Pre & 760 & 1200 \\
\hline & & 651.5 & 94.09 & During & 580 & 880 \\
\hline & & 232.7 & 81.10 & Post & 119 & 340 \\
\hline \multirow{3}{*}{$\begin{array}{l}\text { Space of } \\
\text { activity of } \\
\text { force } \text { EMG }\end{array}$} & \multirow{3}{*}{$\begin{array}{c}\text { Microvolt/seco } \\
\text { nd }\end{array}$} & 96.76 & 21.92 & Pre & 73.1 & 130.5 \\
\hline & & 77.11 & 14.73 & During & 60.2 & 95.8 \\
\hline & & 52.76 & 8.058 & Post & 42.1 & 63.3 \\
\hline
\end{tabular}

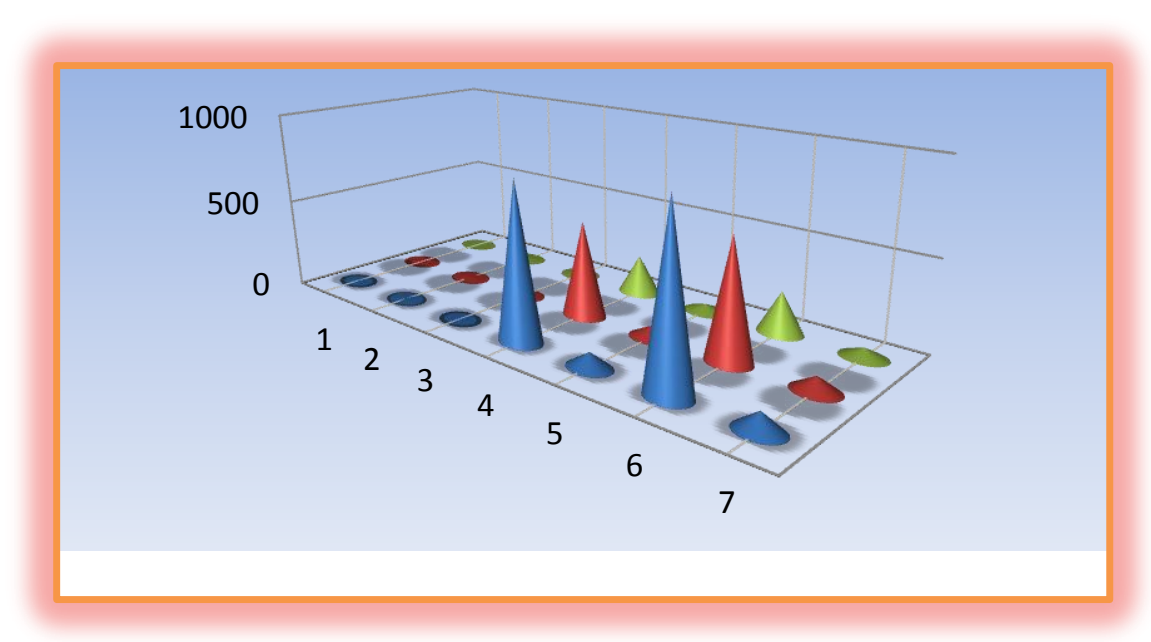

Form (3), shows the amount of sequential evaluation in the studied variables. 
4.1.2. View and analyze the results of tests between the evaluation stages and the average grade of Friedman's calculated grade, significance level and magnitude of impact.

Table (3), the average grade of Friedman's calculated grade, pain level, maximum power, power toleration, peak and space of electrical activity in pre, during and post measurements.

\begin{tabular}{|c|c|c|c|c|c|c|c|}
\hline Tests & Measurements unit & stages & $\begin{array}{l}\text { Grade } \\
\text { average }\end{array}$ & $\begin{array}{c}\text { Friedman's } \\
\text { calculated } \\
\text { grade }\end{array}$ & significance & $\begin{array}{l}\text { Effect } \\
\text { extent }\end{array}$ & $\begin{array}{c}\text { Type of } \\
\text { significance }\end{array}$ \\
\hline \multirow{3}{*}{ Pain level } & \multirow{3}{*}{ One degree } & Pre & 3.00 & \multirow{3}{*}{18} & \multirow{3}{*}{0.000} & \multirow{3}{*}{5.80} & \multirow{3}{*}{ Moral } \\
\hline & & during & 2.00 & & & & \\
\hline & & Post & 1.00 & & & & \\
\hline \multirow{3}{*}{ Maximum power } & \multirow{3}{*}{ Kg } & Pre & 1.00 & \multirow{3}{*}{19.00} & \multirow{3}{*}{0.000} & \multirow{3}{*}{6.12} & \multirow{3}{*}{ Moral } \\
\hline & & during & 2.00 & & & & \\
\hline & & Post & 3.00 & & & & \\
\hline \multirow{3}{*}{ power toleration } & \multirow{3}{*}{ How often } & Pre & 1.00 & \multirow{3}{*}{20.00} & \multirow{3}{*}{0.000} & \multirow{3}{*}{6.45} & \multirow{3}{*}{ Moral } \\
\hline & & during & 2.00 & & & & \\
\hline & & Post & 3.00 & & & & \\
\hline \multirow{3}{*}{$\begin{array}{l}\text { Peak electrical activity of } \\
\text { maximum force EMG }\end{array}$} & \multirow{3}{*}{ Microvolt } & Pre & 3.00 & \multirow{3}{*}{17.00} & \multirow{3}{*}{0.000} & \multirow{3}{*}{5.48} & \multirow{3}{*}{ Moral } \\
\hline & & during & 2.00 & & & & \\
\hline & & Post & 1.00 & & & & \\
\hline \multirow{3}{*}{$\begin{array}{l}\text { Space of electrical activity } \\
\text { of maximum force EMG }\end{array}$} & \multirow{3}{*}{ Microvolt/second } & Pre & 3.00 & \multirow{3}{*}{20.00} & \multirow{3}{*}{0.000} & \multirow{3}{*}{6.45} & \multirow{3}{*}{ Moral } \\
\hline & & during & 2.00 & & & & \\
\hline & & Post & 1.00 & & & & \\
\hline \multirow{3}{*}{$\begin{array}{l}\text { Peak electrical activity of } \\
\text { maximum force EMG }\end{array}$} & \multirow{3}{*}{ Microvolt } & Pre & 3.00 & \multirow{3}{*}{15.00} & \multirow{3}{*}{0.000} & & \\
\hline & & during & 2.00 & & & 4.83 & Moral \\
\hline & & Post & 1.00 & & & & \\
\hline & & Pre & 3.00 & & & & \\
\hline of maximum force EMG & Microvolt/second & during & 2.00 & 19.00 & 0.000 & 6.12 & Moral \\
\hline & gerovotestra & Post & 1.00 & & & & \\
\hline
\end{tabular}

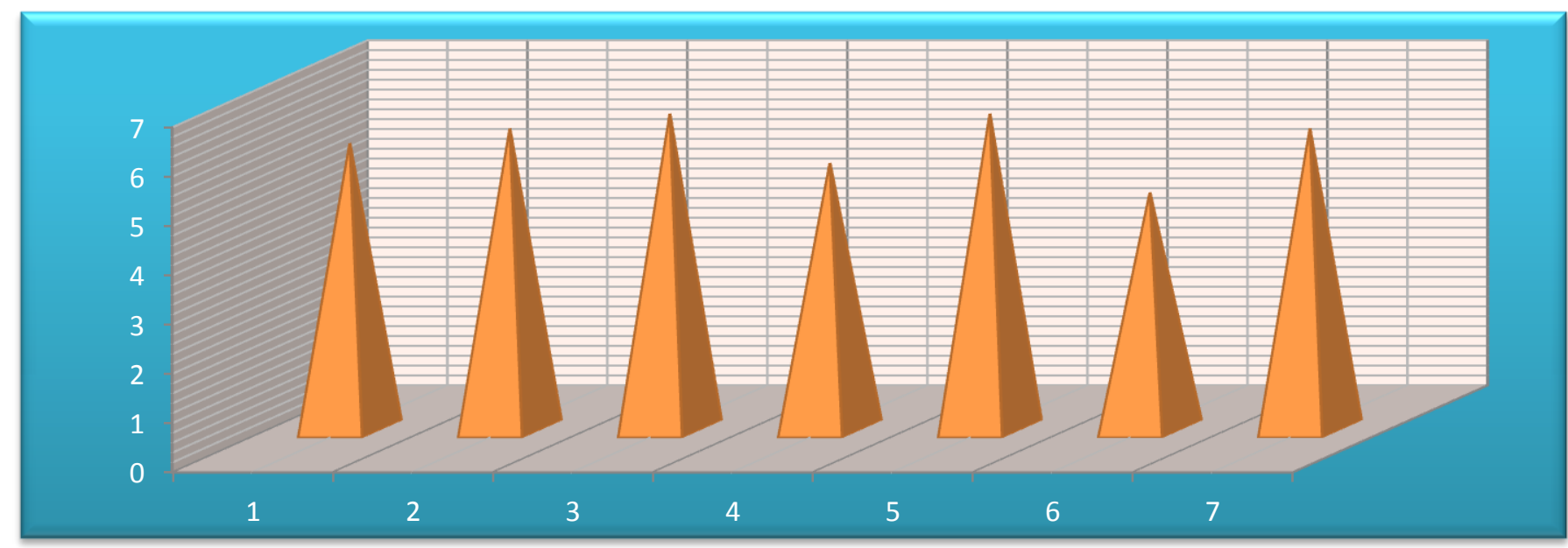

Form (3), shows effect extent of the rehabilitation exercises

Throughout the table (3) it appears the positive effect of the rehabilitation exercises that applied on the pre, during and post tests instead of the moral differences between the three tests and each principal. The statistical means has also been shown by the toleration of effect and high and good levels as the good percentage is more than
$(0.06)^{(5)}$ in all measurements that appeared through the following:

1. In examining the level of pain

The value of the average grade in the pre-test is (3), and (2.00) in the during-test while the posttest is (1). To ensure the moral differences, the researchers has extracted Friedman's value that 
amounted (18.00) in level of (0.000) which is the minimum indication (0.05); that indicates to the moral differences between the pre, during and post measurements for the post test.

2. In examining the maximum power:

The value of the average grade in the pre-test is (1), and (2.00) in the during-test while the posttest is (3). To ensure the moral differences, the researchers has extracted Friedman's value that amounted (19.00) in level of (0.000) which is the minimum indication (0.05); that indicates to the moral differences between the pre, during and post measurements for the post test.

3. In examining the power toleration:

The value of the average grade in the pre-test is (1), and (2.00) in the during-test while the posttest is (3). To ensure the moral differences, the researchers has extracted Friedman's value that amounted (20.00) in level of (0.000) which is the minimum indication (0.05); that indicates to the moral differences between the pre, during and post measurements for the post test.

4. In examining the electrical activity EMG (peak and space) of the maximum power:

The value of the average grade in the pre-test is (3), and (2.00) in the during-test while the posttest is (1). To ensure the moral differences, the researchers has extracted Friedman's value that amounted (17.00) in level of (0.000) which is the minimum indication (0.05); that indicates to the moral differences between the pre, during and post measurements for the post test 'On the other hand, the value of the average grade of the space principal in the pre-test is (3), and (2.00) in the during-test while the post- test is (1).; whereas the Friedman's value amounted (20.00) in level of $(0.000)$ which is the minimum indication (0.05); that indicates to the moral differences between the pre, during and post measurements for the post test.

4.1.2. Discussion the results of pain level, maximum power, power toleration and peak and space of electrical activity in pre, during, post measurements and Friedman's value:
Throughout the notes of average grade and Friedman's value calculated that appeared in table no. 3 in the standards tests of pain level, maximum power, power toleration and electrical power EMG (peak and space) of the maximum power'However, through the results shown in table (3), we note that there exists a notable development in the body standards and the function of Supraspinatus muscle animation within the pre, during and post results to the post measurements; so by such, the researchers refer to the following:

The researchers ensure that the role of rehabilitation exercises and its various performances perform a positive role in repetition of the injured sinew and the working muscles in the shoulder's joint. The rehabilitation moving activities and their use contribute in increasing the muscular power for the injured part to be as equal as much to the sound part. ${ }^{(6)}$

The researchers noted a clear contradiction in the percentage of electrical sign of the deltoid within the pre, during and post tests; and it is for the benefit of the post test in EMG, space of the electrical power of muscles. Through that the researchers refer to the following:

The rehabilitation program and the type of performed activities that stands on educational principals lead to difference morals between the tree measurements. The shoulder joint exercise stands on training the muscles working in the shoulder joint. The period of the rehabilitation exercises included the diversity of units to increase the moral and psychological status of the player and the commitment by the players to work during the time of rehabilitation exercises. That led to increase the ability of shoulder muscles with muscles fiber to perform; the ability of sinew and the rotated-shoulder muscle to fatigue resistance. However, Mhammed Hassan Alawi and Nasraldin Radwan has ensured that the muscle power is considered to be one of the important adjectives and what resulting through it in increasing the muscle toleration that depends on 
the power and sound contribution between them and the nervous system. ${ }^{(7)}$

The resources indicate that the regular training produces increasing in the individual power due to the body exercises for days, weeks or months by normalizing the body jutting on a perfect performance of such exercises. In other words, the effects of body exercises stimulate cells for imprinting and being more economic performance in the severity of scariness ${ }^{(8)}$ Hence, the researchers finds that the muscle become more exciting to the moving units through the developing the of functional work of the muscle sinew, however, the essential aim of the rehabilitation exercises is to make physiological adjustment in the muscles involved in the shoulder joint. These adjustment produce development in the type of muscles fiber involved in muscles contraction as well as development of the characteristics of the concerned motor units. It is pointed that the performance of any movement is related to the corporation of the motor units in the muscular work where the more number of units the more increased in the muscular power, To the wave under the electric curve, the researchers has found the occurred development in which due to the muscle sinew increasing; that means the more resistance with the help of numbers of motor fibers the less of physical, physiological and biochemical burden. However, the researchers found a contradiction within the signal of the maximum electrical activity (EMG) due to the less required effort of the muscular neuropathy and the ability is the power required production in minimum time; that led to power stimulation because of the refinement and centralization of work that also led to a minimizing in the electrical activity space. Saad Sadon has pointed out that is due to calculate the power of stimulus in the time of constriction. Omar (2012) has also pointed out that there exists nervous activity occurred due to the effect of muscular activity; that work on contributing a large number of muscular fibers in the movement performance in which lead to increasing the power level without increasing the muscular mass ${ }^{(9)}$.

Testing the variable of electrical activity (EMG) to withstand the force, (peak and space):

Through the results noted in the table (2), the researchers noticed that there exists a great development in the average of the electrical sign to the Supraspinatus muscle animation within the three tests in the benefit of the post test. The researchers refer to that the cause of such a development is the required resistance of the muscular work in the post measurement. That means the muscle was not able to work for a long time, so it is unable to have largest number of units for the required work. The toleration was having a positive return in developing the power toleration of the deltoid. However, the main goal of this method is to develop the toleration as the muscle activity increases whenever it has an exercise. The rehabilitation program has led to increase the participation of the largest number of motor units in the muscle work. The muscle shows a suitable resistance for performing the required movements. Hence, there is a contradiction in the maximum signal power that makes it more regular; this what (Adama and Deluca 2005) have ensured (10). When the muscular fibers get tired, the effort of the individual is increased by sharing more motor units ${ }^{(11)}$.

\section{The Wave Under the Electric Curve:}

The researchers have found that the space of the space under the curve varied by different period of the performance where the maximum work extends longer in which directly proportional to the top of the electrical signal. Mohammed Mageed has pointed that the greater the time period, the greater the area of the curve, because it is the result of two variables which are the high level of peak activity and the time of this summit (11). 


\section{Findings and recommendations}

\subsection{Findings}

According to the goals and hypothesis, community, repulsive procedures, statistical results of collected data and the under consideration variables of the study, the researchers have found the following:

1. The rehabilitation exercises have a positive effect on the rehabilitation of the sinew inflammation of supraspinatus muscle animation.

2. The rehabilitation exercises have a positive effect on the power and toleration of supraspinatus muscle animation; therefore, it reflected on the development of the muscle work physically and functionally.

3. The rehabilitation exercises have a positive effect on the development of the muscles working on the shoulder joint in terms of some physical and functional variables.

\subsection{Recommendations}

1. Practicing the rehabilitation exercises that were made for the inflammation sinew of the muscles working on the shoulder joint.

2. Accreditation the measurements of the level of electrical activity of muscles (EMG); in order to diagnose cases of muscles injuries as they are important and accurate diagnostic tools.

3. Attentions to the testes of the dynamic activity of the electrical muscle with similar studies include different samples.

\section{References}

1. Albasiri E., sport injuries, Bagdad, Alhoria publishing, 2000.

2. Abdulfatah A. Ahmed, sport exercises, physiological basics, Qiro, Dar Alfikr Alarabi, 2001.

3. Gawad S. Sadoon, the effect of toleration activity in developing some physical, functional and skillful abilities of football players aged 15 , Ph.D thesis, faculty of physical education, Bagdad University, 2011.

4. Mohammed S. Khalil, sport injuries, ministry of higher education, Bagdad University, 2005.

5. Salal, M. Majed, a study of electrical activity of leg muscle for free click and some biochemical standards and its relation with goals, Ph.D thesis, Bagdad University, 2012.

6. Albashtawi, M. Hasan and Alkhwaga, A. Ebraim, principals of modern sport activity, Palestine, Alwaiel, 2010.

7. Husain,A. Ali, sport and health, Alskandria, Dar Almarief publishing, 2013.

8. Yasser, E. Kadhim, physiological and mechanical tests and educational basics, Amman, Dar Nagla publishing, 2017.

9. Yasser, O. Khaled, the effect of different motor activities in terms of electrical activity of muscle in developing the percentage power and some physiological standards for lower limbs, master degree, Bagdad University, faculty of physical education, 2012.

10. Alexander Adam and Carlo J. De Luca. Firing rates of motor units in human vastuslateralis muscle during fatiguing. isometric contractions. J ApplPhysiol 99: 268-280, 2005.

11. Janet L. Taylor and Simon C. Gandevia. A comparison of central aspects of fatigue in sub maximal and maximal. voluntary contractions. J Appl Physiol 104: 542550, 2008. P545. 